\title{
Modelización del oleaje a muy altas resoluciones: modelo SWAN
}

https://doi.org/10.31978/639-19-010-0.413

\author{
Ángel Martínez Ferrer ${ }^{1}$ (amartinezf@aemet.es)
}

${ }^{1}$ AEMET / Dirección de Producción e Infraestructuras / Área de Aplicaciones

\section{RESUMEN}

La naturaleza física del oleaje varía sustancialmente de las aguas profundas a las someras, cuyo límite está determinado por el periodo de las olas en cada momento y lugar. El actual estado del arte de los modelos prioriza su aplicabilidad en una determinada profundidad. Por tanto, hay que cambiar de modelo al transitar de la alta mar — donde se genera el oleaje de fondo- a las zonas costeras — donde el oleaje sufre transformaciones más complejas y se encuentran gran parte de los usuarios de predicciones del oleaje-.

En la actualidad AEMET tiene implementada la integración en dominios anidados por WW3 con resoluciones 24'-12'-6'-3'-1,5'. Esta ponencia presenta estudios en los que WW3 traspasa condiciones de contorno en forma de espectros 2-D de la energía a dominios locales costeros para que SWAN (Simulating Waves Near Shore) integre con resoluciones de 1' e inferiores.

Por último, la zona de rompientes del oleaje está caracterizada por parámetros adicionales a la altura significativa y dirección de propagación, tales como el tipo de rotura y las corrientes laterales a la línea de costa. AEMET aplicará el modelo hidrodinámico XBeach que recibe datos de contorno desde SWAN en ciertas playas de España.

Para incorporar la realidad de la dinámica oceánica, el esquema de predicción integrada de AEMET fuerza el oleaje además con campos de corrientes y marea astronómica. El modelo NEMO proporciona estos campos a una resolución espacial de 5/3'. El modelo SWAN permite aumentar la resolución espacial a Dx < 1' en entornos locales. Por congruencia con la precisión perseguida, son necesarias fuentes de batimetría y vientos a resoluciones similares y así no abusar de la interpolación. La malla ETOPO a 1' es la fuente más fiable de batimetría actualmente. En formato vectorial hay disponibles cartas náuticas electrónicas junto a la costa de cierta antigüedad. Otras instituciones han efectuado campañas de sondeos a muy alta resolución. En viento, AEMET dispone del modelo HARMONIE de área local a $2500 \mathrm{~m}$, con estudios para obtener mallas inferiores a $1000 \mathrm{~m}$.

PALABRAS CLAVE: predicción numérica; modelos de oleaje; esquema implícito; aguas someras; Simulating Waves Near Shore; rompientes; XBeach. 
